Check for updates

Cite this: RSC Adv., 2021, 11, 9290

Received 1st January 2021 Accepted 8th February 2021

DOI: 10.1039/d1ra00010a

rsc.li/rsc-advances

\section{A 3,5-dinitropyridin-2yl substituted naphthalimide- based fluorescent probe for the selective detection of biothiols and its application in cell-imaging $\dagger$}

\author{
Yihua Zhuo, ${ }^{a}$ Yanyu Zhang, ${ }^{a}$ Yadong Feng, (D) ab Yuqing Xu, ${ }^{\star c}$ Qihua You, (DD *ab \\ Lei Zhang, ' Huabin Huang ${ }^{a}$ and Lili Lin*ab \\ A naphthalimide-based fluorescent probe was developed for the sensitive and selective detection of \\ biothiols. The fluorescence of the probe was quenched by the electron-withdrawing 3,5-dinitropyridin- \\ 2-yl group via the photoinduced electron transfer process, and turned on by biothiol-triggered \\ nucleophilic aromatic substitution. The sensing mechanism was confirmed by HPLC analysis and \\ theoretical calculations. The probe shows a satisfactory response time of 30 min with low detection \\ limits (Cys: $0.32 \mu \mathrm{M}$; Hcy: $0.88 \mu \mathrm{M}$; GSH: $0.46 \mu \mathrm{M}$ ). Furthermore, the probe was successfully utilized to \\ detect endogenous and exogenous biothiols in HeLa cells.
}

\section{Introduction}

Biological thiols (biothiols), including cysteine (Cys), homocysteine (Hcy), and glutathione (GSH), are found to be closely associated with many diseases., ${ }^{\mathbf{1 , 2}}$ For example, an abnormal level of Cys is relevant to skin lesions, liver damage, brain injury, and Parkinson's disease. ${ }^{3}$ A high concentration of Hcy has been reported to be linked to cardiovascular disease, osteoporosis, and Alzheimer's disease. ${ }^{4-6}$ As the most abundant biothiol and an important antioxidant in cells, the decrease of GSH is associated with neurodegeneration, inflammation, and so forth. ${ }^{7-9}$ Therefore, the development of highly selective and sensitive detection methods for biothiols is important for the early diagnosis of diseases.

Fluorescent probes have attracted wide attention due to their high selectivity and sensitivity, real-time detection, noninvasiveness, and biocompatibility characteristics. ${ }^{\mathbf{1 0 - 1 3}}$ In the development of a fluorescent probe for biothiol sensing, the design strategies are mainly focused on Michael addition, ${ }^{\mathbf{1 4 - 1 6}}$ nucleophilic cleavage-cyclization, ${ }^{17-19}$ metal coordination complex-displacement, ${ }^{20-22}$ and nucleophilic aromatic substitution (SNAr). ${ }^{23-26}$ Giving the strong nucleophilicity of biothiols, especially their corresponding deprotonated thiolate anion, it is

${ }^{a}$ College of Environment and Public Health, Xiamen Huaxia University, 288 Tianma Road, Jimei District, Xiamen 361024, P. R. of China.E-mail: jyyqh@hxxy.edu.cn

${ }^{b}$ Biochemical Pharmacy Engineering Research Center of Fujian Province University, 288 Tianma Road, Jimei District, Xiamen 361024, P. R. of China

${ }^{c}$ School of Physics and Optoelectronics Engineering, Ludong University, Yantai 264025, P. R. of China

${ }^{d}$ Biology Institute of Shanxi, 50 Shifan Road, Xiaodian District, Taiyuan 030006, P. R. of China

$\dagger$ Electronic supplementary information (ESI) available. See DOI: 10.1039/d1ra00010a desirable to introduce a strong electron-withdrawing group as a biothiol recognition site to a fluorophore platform. The introducing group also provides a quenching effect via photoinduced electron transfer (PET) mechanism. Hence, a probe can be designed with high reactivity and sensitivity toward biothiols. Recently, 3,5-dinitropyridin-2-yl was chosen as a biothiol recognition site due to its higher electron-withdrawing ability than other commonly used groups such as 2,4-dinitrophenyl, 2,4-dinitrobenzenesulfonyl and 7-nitro-2,1,3-benzoxadiazole group. ${ }^{24}$ This biothiol recognition group exhibited satisfactory selectivity and sensitivity toward biothiols in aqueous buffer and living cells. Therefore, it is necessary to extend the application of this recognition group to improve its sensing ability in the design of a biothiol-targeting fluorescent probe.

In this work, we report a new fluorescent probe for the detection of biothiols based on the nucleophilic aromatic substitution. $N$-Butyl-4-hydroxy-1,8-naphthalimide (NAP-OH) was selected as the fluorophore due to its high photostability, and good biocompatibility. ${ }^{27,28}$ NAP-DNP exhibits high selectivity and sensitivity for biothiols with low detection limits (0.32 $\mu \mathrm{M}, 0.88 \mu \mathrm{M}$ and $0.46 \mu \mathrm{M}$ for Cys, Hcy and GSH, respectively) and medium response $(30 \mathrm{~min})$. The proposed recognition mechanism was corroborated by HPLC analysis and theoretical calculations. The low cell cytotoxicity indicates that NAP-DNP is suitable for the sensing of biothiols in living cells.

\section{Results and discussion}

\subsection{The synthesis of NAP-DNP}

Probe NAP-DNP was synthesized by the reaction of NAP-OH with 2-chloro-3,5-dinitropyridine in a 72\% yield, as shown in Scheme 1. The product was fully characterized by ${ }^{1} \mathrm{H}$ NMR, ${ }^{13} \mathrm{C} \mathrm{NMR}$, and HRMS analysis. Detailed synthetic procedure and structure 


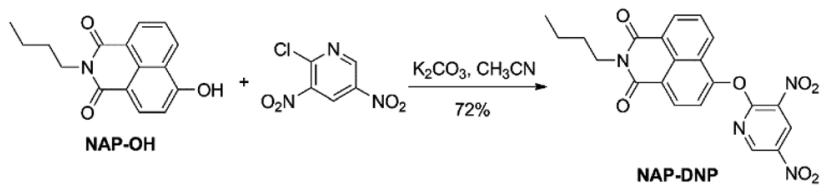

Scheme 1 Synthetic route to probe NAP-DNP.

characterizations are given in the experimental section and the ESI (Fig. S1-S3†).

\subsection{The selectivity of NAP-DNP for biothiols}

The absorption and emission responses of NAP-DNP $(10 \mu \mathrm{M})$ toward various amino acids were investigated in Tris buffer (20 mM, pH 7.4, containing 10\% DMSO, v/v). As shown in Fig. 1, NAP-DNP exhibited a weak absorption band centered at $450 \mathrm{~nm}$ in the visible range and a weak emission band centered at $550 \mathrm{~nm}$. Upon addition of biothiols (Cys, Hcy and GSH), the absorbance and fluorescence intensity increase to some extent (7.0-, 2.8- and 3.4-fold enhancement in fluorescence intensity for Cys, Hcy and GSH, respectively). Meanwhile, the solution of NAP-DNP changed from colorless to pale yellow (inset of Fig. 1a) and emitted distinct lemon-yellow fluorescence under UV lamp (inset of Fig. 1b). In contrast, other amino acids including Ala, Asn, Asp, Arg, Gln, Glu, Gly, His, Ile, Leu, Lys, Met, Phe, Pro, Ser, Thr, Trp, Tyr and Val, induced negligible change in absorbance and fluorescence intensity of NAP-DNP. Also, the presence of the abovementioned amino acids $(200 \mu \mathrm{M})$ has no significant effect on the sensing ability of NAP-DNP to biothiol (Fig. 2). These results indicate that NAP-DNP is a highly selective fluorescent probe for biothiols.

\subsection{The sensitivity of NAP-DNP for biothiols}

To investigate the sensing ability of NAP-DNP for biothiols (Cys as the representative), titration experiments were conducted with UV-Vis and fluorescence spectroscopy. As shown in Fig. 3a and $4 \mathrm{a}$, upon addition of Cys, the absorption peak at $450 \mathrm{~nm}$ and fluorescence intensity at $550 \mathrm{~nm}$ increased gradually and reached a plateau after the addition of $200 \mu \mathrm{M}$ of Cys (Fig. 3b and $4 \mathrm{~b})$. A linear relationship $\left(R^{2}=0.994\right)$ was found between the fluorescence intensity at $550 \mathrm{~nm}$ and Cys concentration in
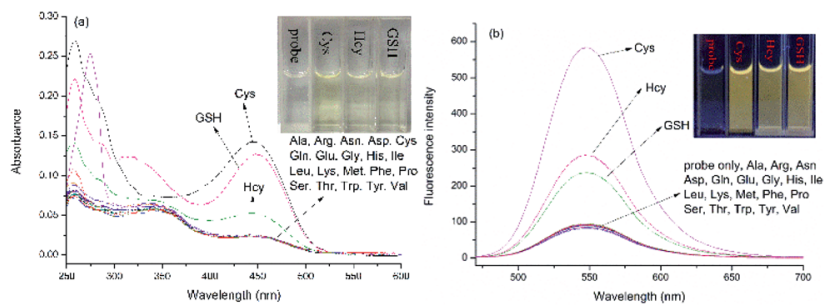

Fig. 1 UV-Vis absorption (a) and fluorescence (b) spectra of NAP-DNP $(10 \mu \mathrm{M})$ in DMSO-Tris buffer $(1: 9, \mathrm{v} / \mathrm{v}, 20 \mathrm{mM}, \mathrm{pH}=7.4)$ upon addition of different amino acids $(200 \mu \mathrm{M})$. Inset: color of solution (a) and fluorescence (b) changes of NAP-DNP without and with different biothiols (Cys, Hcy and GSH).

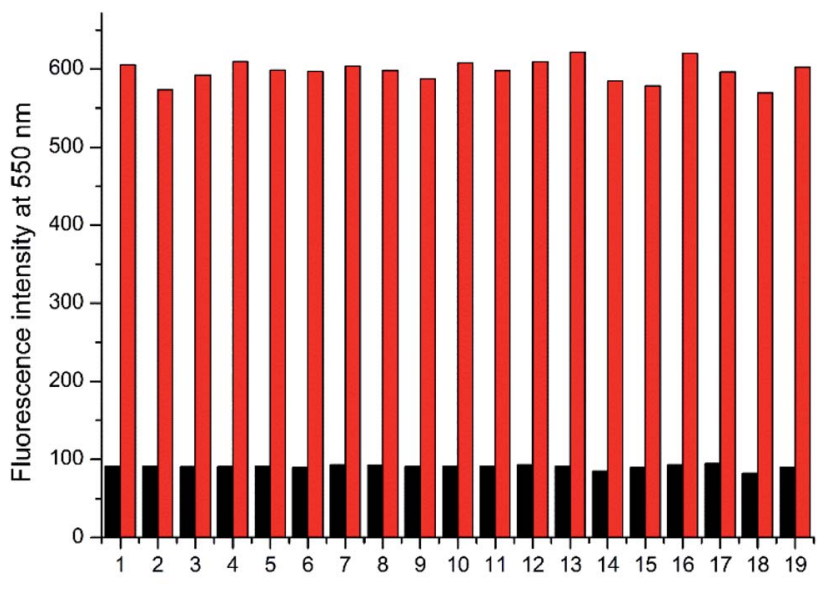

Fig. 2 Fluorescence intensity changes of NAP-DNP $(10 \mu \mathrm{M})$ for Cys in the presence of various amino acids $(200 \mu \mathrm{M})$ in DMSO-Tris buffer $(1: 9, v / v, 20 \mathrm{mM}, \mathrm{pH}=7.4)$ for $30 \mathrm{~min}\left(\lambda_{\mathrm{ex}} / \lambda_{\mathrm{em}}=450 / 550 \mathrm{~nm}\right)$. Black bars represent the addition of a single analyte including (1) Ala; (2) Arg; (3) Asn; (4) Asp; (5) Gln; (6) Glu; (7) Gly; (8) His; (9) lle; (10) Leu; (11) Lys; (12) Met; (13) Phe; (14) Pro; (15) Ser; (16) Thr; (17) Trp; (18) Tyr; (19) Val. Red bars represent the subsequent addition of Cys $(200 \mu \mathrm{M})$ to the mixture.

the range of $0-40 \mu \mathrm{M}$ (inset of Fig. $4 \mathrm{~b}$ ), suggesting that NAP-DNP is capable of sensing biothiols both qualitatively and quantitatively. The detection limit $(3 \sigma / k)$ of NAP-DNP for Cys, Hcy and GSH was measured to be $0.32 \mu \mathrm{M}, 0.88 \mu \mathrm{M}$ and $0.46 \mu \mathrm{M}$, respectively (inset of Fig. 4b, S4 and S5†). The values are lower than that of many reported biothiol probes, indicating that NAP-DNP is highly sensitive to biothiols.

\subsection{The effect of $\mathrm{pH}$ and time-dependent response}

To evaluate the sensing $\mathrm{pH}$ range for NAP-DNP, fluorescent detection of Cys at different $\mathrm{pH}$ values was investigated. As shown in Fig. 5, NAP-DNP exhibits a very weak fluorescence under strong or moderate acidic conditions $(\mathrm{pH}<5)$, and a slight enhancement in fluorescence intensity over a pH range from 6 to 8. However, a significant fluorescence enhancement was observed at $\mathrm{pH}$ over 9 . These results may be ascribed to the strong electron-withdrawing 3,5-dinitropyridin-2-yl group facilitating the nucleophilic attack by $\mathrm{OH}^{-}$. In the presence of Cys $(200 \mu \mathrm{M})$, the fluorescence intensity of NAP-DNP increased

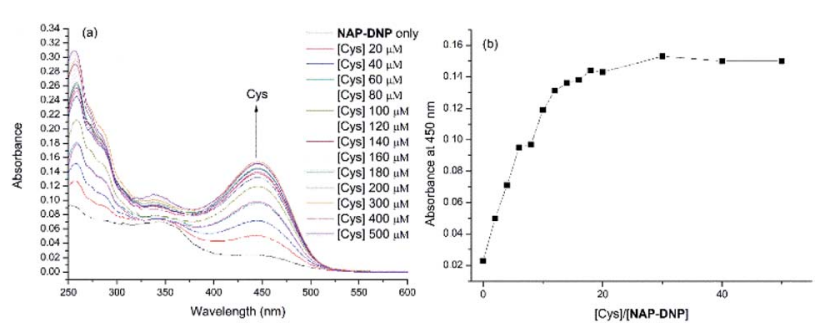

Fig. 3 (a) UV-Vis absorption titration of NAP-DNP $(10 \mu \mathrm{M})$ in DMSOTris buffer (1 : 9, v/v, $20 \mathrm{mM}, \mathrm{pH}=7.4)$ upon addition of Cys. (b) Plot of absorbance at $450 \mathrm{~nm}$ of NAP-DNP $(10 \mu \mathrm{M})$ as a function of Cys concentration. 

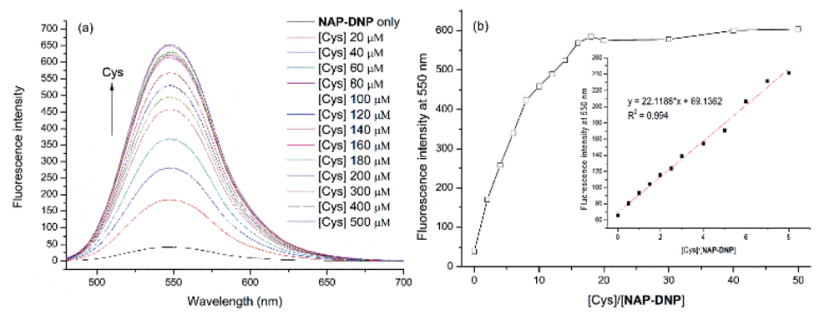

Fig. 4 (a) Fluorescence titration of NAP-DNP $(10 \mu \mathrm{M})$ in DMSO-Tris buffer $(1: 9, \mathrm{v} / \mathrm{v}, 20 \mathrm{mM}, \mathrm{pH}=7.4)$ upon addition of Cys. Excitation wavelength is set at $460 \mathrm{~nm}$. Excitation/emission wavelength slit $=5 /$ $3 \mathrm{~nm}$. (b) Plot of fluorescence intensity at $550 \mathrm{~nm}$ of NAP-DNP $(10 \mu \mathrm{M})$ as a function of Cys concentration. Inset: plot of the linear relationship $\left(R^{2}=0.994\right)$ between the fluorescence intensity at $550 \mathrm{~nm}$ of NAP$\operatorname{DNP}(5 \mu \mathrm{M})$ and Cys concentration $(0,0.5,1.0,1.5,2.0,2.5,3.0,4.0,5.0$, $6.0,7.0,8.0$ equiv.).

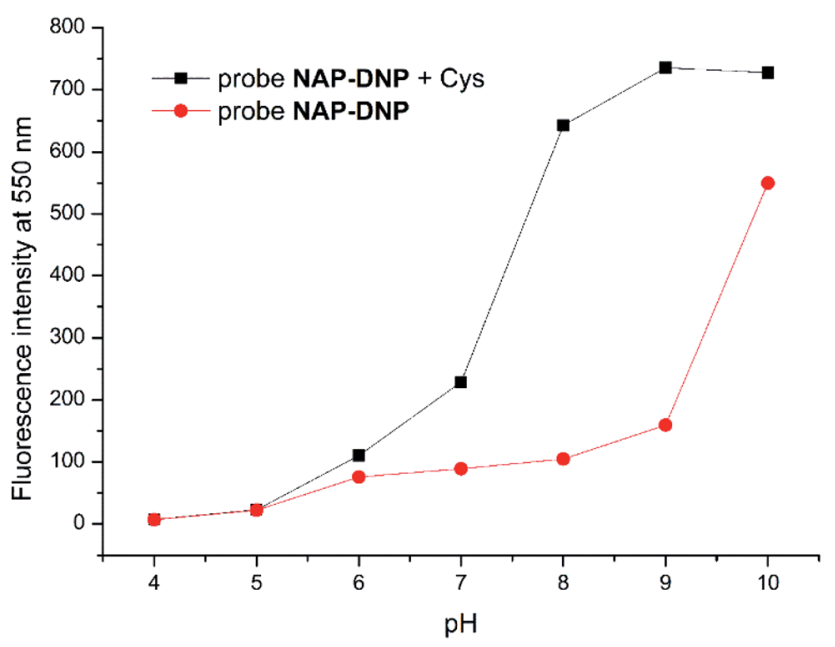

Fig. 5 Fluorescence intensity at $550 \mathrm{~nm}$ of probe NAP-DNP $(10 \mu \mathrm{M})$ in DMSO-Tris buffer (1: 9, v/v, $20 \mathrm{mM}, \mathrm{pH}=7.4$ ) without (red circle) and with (black square) addition of Cys $(200 \mu \mathrm{M})$ as a function of $\mathrm{pH}$.

gradually when the $\mathrm{pH}$ increased from 5 to 9 and reached a steady reading at $\mathrm{pH}$ over 9 . Considering the ratio of fluorescence intensity of NAP-DNP with Cys to the fluorescence intensity of NAP-DNP at different $\mathrm{pH}$ values (Fig. S6†) and further application in cell-imaging, physiological $\mathrm{pH}$ at 7.4 was selected throughout the experiments. The time-dependent responses of NAP-DNP to biothiols were also investigated (Fig. 6). It was found that the fluorescence output of NAP-DNP became steady after $30 \mathrm{~min}$ addition of biothiols at $\mathrm{pH}$ 7.4. Therefore, all of the experiments were measured after the addition of biothiols for $30 \mathrm{~min}$.

\subsection{Sensing mechanism}

To test the hypothesis on the biothiol-triggered activation of NAP-DNP, the reaction of NAP-DNP with Cys was analyzed via HPLC. As shown in Fig. 7, NAP-DNP, NAP-OH and 2-chloro-3,5dinitropyridine displayed a single peak with a retention time at $11.07,4.38$ and $3.50 \mathrm{~min}$, respectively. Upon the addition of Cys to the solution of NAP-DNP for $15 \mathrm{~min}$, the peak at $11.34 \mathrm{~min}$

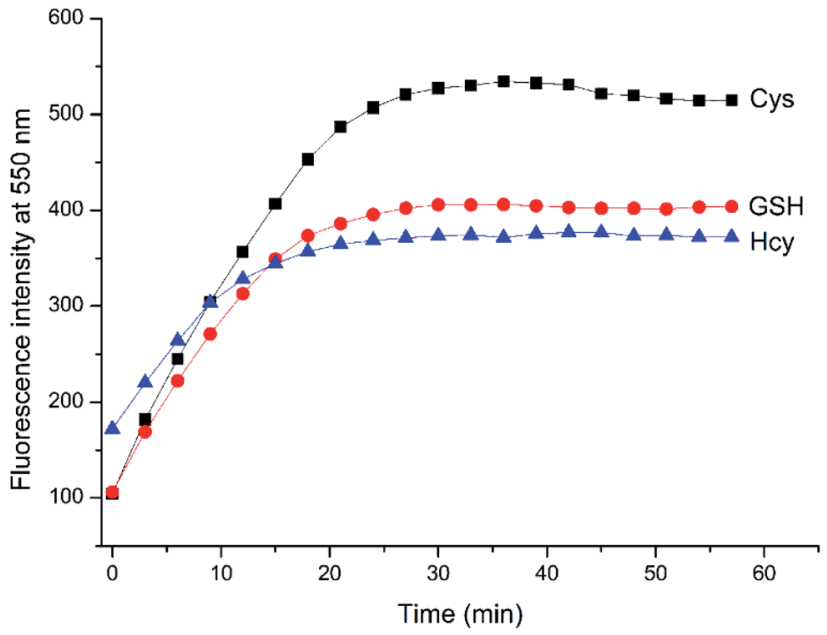

Fig. 6 Time-dependent fluorescence enhancement at $550 \mathrm{~nm}$ of NAP-DNP $(10 \mu \mathrm{M})$ in DMSO-Tris buffer $(1: 9, \mathrm{v} / \mathrm{v}, 20 \mathrm{mM}, \mathrm{pH}=7.4)$ upon the addition of various Cys, Hcy and GSH $(200 \mu M)$, respectively.

weakened while peaks at 1.43 and 4.43 min emerged (Fig. 7e). After reaction for $30 \mathrm{~min}$, the peak at $11.34 \mathrm{~min}$ disappeared while peaks at 1.75 and 4.45 min strengthened (Fig. 7f). The peak at $1.75 \mathrm{~min}$ is in accordance with the result of the reaction of 2-chloro-3,5-dinitropyridine with Cys (Fig. 7d). This result confirmed the proposed sensing mechanism (Scheme 2) that the fluorescence enhancement of NAP-DNP in the presence of Cys is ascribed to the release of molecule NAP-OH from NAPDNP.

\subsection{Theoretical calculations}

To prove our speculation of the proposed sensing mechanism, density functional theory (DFT)-based theoretical calculations

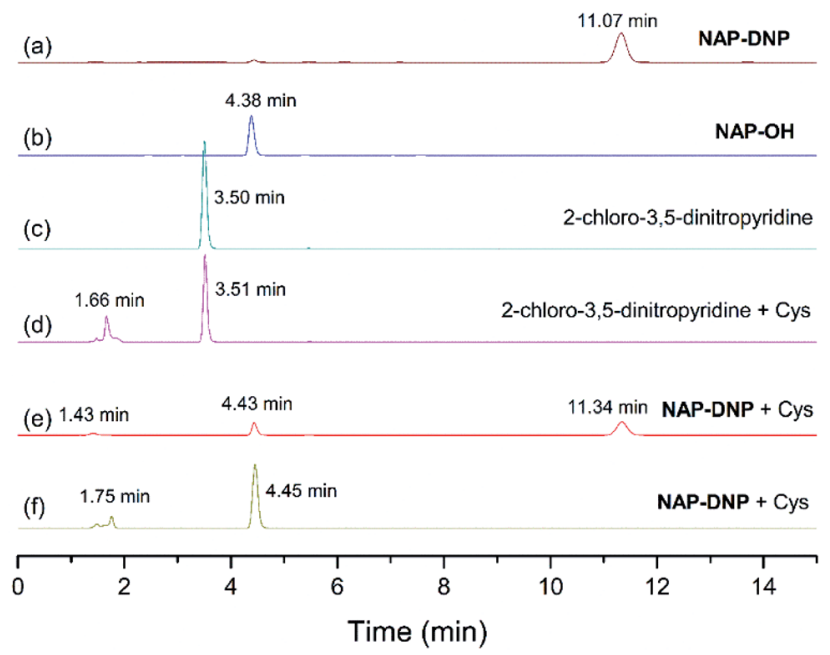

Fig. 7 The reversed-phase HPLC with absorption (254 nm) detection. (a) Probe NAP-DNP. (b) Compound NAP-OH. (c) 2-Chloro-3,5-dinitropyridine. (d) The reaction mixture of 2-chloro-3,5-dinitropyridine and Cys. (e) The reaction mixture of NAP-DNP and Cys for 15 minutes. (f) The reaction mixture of NAP-DNP and Cys for 30 minutes. 


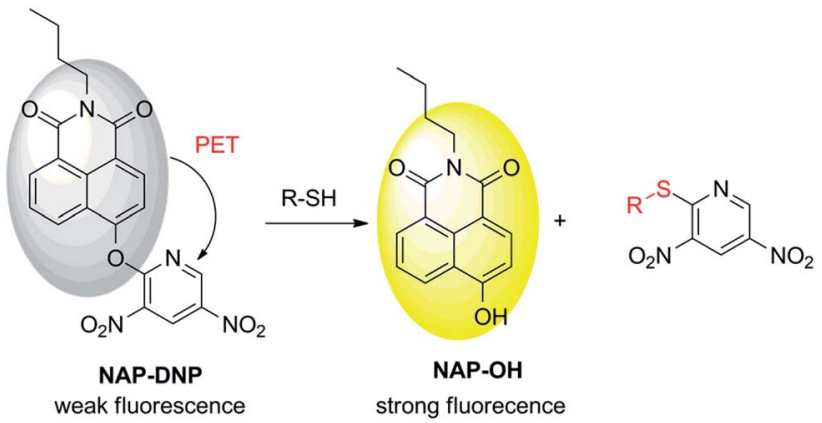

Scheme 2 Proposed mechanism for sensing of biothiols.

were carried out using Gaussian 16, C.01 program. ${ }^{29}$ The energyoptimized geometries and electronic structure of NAP-DNP and NAP-OH were generated by using B3LYP/6-31G(d) basis set, respectively. The computational results revealed that in NAPDNP, the highest occupied molecular orbital (HOMO) was mainly located on the electron-donating naphthalimide moiety, whereas the lowest unoccupied molecular orbital (LUMO) was located primarily on the 3,5-dinitropyridin-2-yl moiety (Fig. 8). The energy level of LUMO and HOMO demonstrated that electrons could transfer from the naphthalimide moiety to the 3,5dinitropyridin-2-yl moiety when NAP-DNP was excited, which corresponds to the fluorescence quenching of NAP-DNP. However, when NAP-DNP was converted to NAP-OH by biothiol, both the HOMO and LUMO were mainly located on the naphthalimide moiety. Therefore, the electron transfer process was inhibited and the fluorescence was in the "turn-on" state. These results are in reasonable agreement with the experimental results.

\subsection{Imaging of biothiols in living cells}

Encouraged by the above experimental results, a further application of NAP-DNP for the sensing of biothiols in living cells was conducted. Initially, we evaluated the cytotoxicity of NAP-DNP at various concentrations using the CCK-8 assay (Fig. S7 $\dagger$ ). Living HeLa cells were incubated with different concentrations of NAPDNP $(0,5,10,20,50 \mu \mathrm{M})$ for $24 \mathrm{~h}$ at $37^{\circ} \mathrm{C}$, with the results

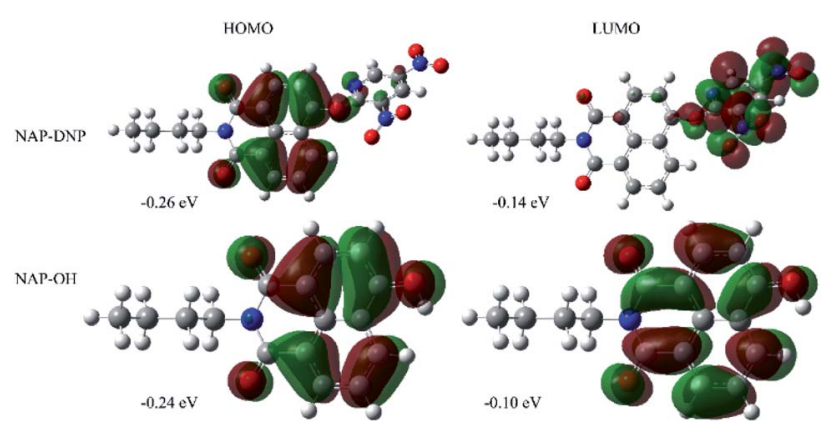

Fig. 8 Electron density distributions in the $\mathrm{HOMO}$ and LUMO states of NAP-DNP and NAP-OH calculated by DFT in Gaussian 16, C.01 program.

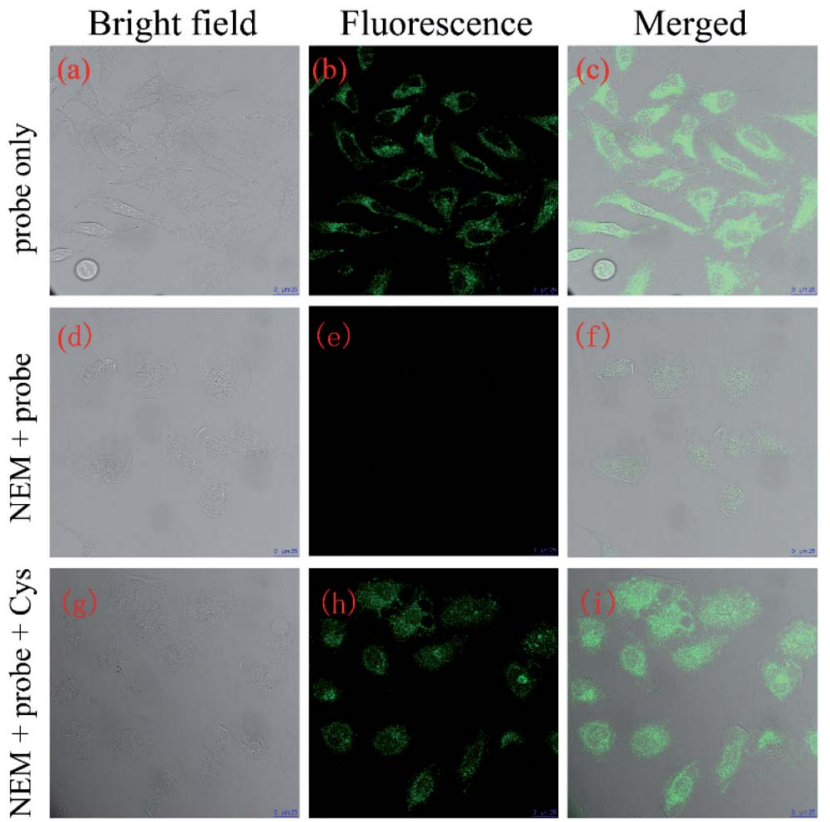

Fig. 9 Confocal microscopy images of HeLa cells. (a-c) HeLa cells incubated with probe NAP-DNP $(10 \mu \mathrm{M})$ for $30 \mathrm{~min}$; $(\mathrm{d}-\mathrm{f})$ HeLa cells pretreated with NEM $(5 \mathrm{mM})$ for $30 \mathrm{~min}$ and further incubated with NAP-DNP $(10 \mu \mathrm{M})$; $(\mathrm{g}-\mathrm{i})$ HeLa cells pretreated with NEM $(5 \mathrm{mM})$ for $30 \mathrm{~min}$ and then incubated with NAP-DNP $(10 \mu \mathrm{M})$ and Cys $(10 \mathrm{mM})$ for 30 min ( $a, d$ and g): bright field image; (b, e and h): fluorescence image collected in the range of 500-600 nm; (c, $f$ and i): overlap of bright field and fluorescence image. Excitation wavelength: $488 \mathrm{~nm}$ scale bar: $25 \mu \mathrm{m}$.

suggesting that NAP-DNP has very low cytotoxicity to HeLa cells, even at high concentration.

The reaction time of NAP-DNP for biothiols was determined to be $30 \mathrm{~min}$, which indicated that NAP-DNP is suitable for the real-time detection of biothiols in living cells. When HeLa cells were incubated with NAP-DNP $(10 \mu \mathrm{M})$ at $37{ }^{\circ} \mathrm{C}$ for $30 \mathrm{~min}$, strong fluorescence was observed (Fig. 9a-c). Considering that the high concentrations of intracellular biothiols (Cys: 30-200 $\mu \mathrm{M}$; Hcy: 5-12 $\mu \mathrm{M}$; GSH: $1-20 \mathrm{mM}){ }^{30,31}$ it could be concluded that the fluorescence enhancement was mainly caused by the reaction of NAP-DNP with intracellular biothiols. As a control, no fluorescence was observed for cells pre-incubated with $N$ ethylmaleimide (NEM, a thiol scavenger) (Fig. 9d-f). Furthermore, when HeLa cells were successively treated with NEM, NAP-DNP and Cys, a bright fluorescence was observed (Fig. 9gi). These experiments demonstrated that NAP-DNP can be utilized as an efficient tool to monitor exogenous and endogenous biothiols in living cells.

\section{Conclusions}

In summary, we have successfully developed a turn-on fluorescent probe NAP-DNP for the sensing of biothiols based on the nucleophilic aromatic substitution mechanism. The probe displays high selectivity to discriminate between biothiols and other amino acids. Moreover, the probe shows a satisfactory response time of $30 \mathrm{~min}$ with low detection limits (Cys: $0.32 \mu \mathrm{M}$; 
Hcy: $0.88 \mu \mathrm{M}$; GSH: $0.46 \mu \mathrm{M})$. In particular, the sensing mechanism of the probe to biothiols was investigated via HPLC analysis and theoretical calculations. Furthermore, the probe shows very low cytotoxicity to living cells and has been successfully used for the detection of endogenous and exogenous biothiols.

\section{Experimental}

\subsection{Synthesis of probe NAP-DNP}

To a solution of compound NAP-OH $(270 \mathrm{mg}, 1.0 \mathrm{mmol})$ and 2chloro-3,5-dinitropyridine (205 $\mathrm{mg}, 1.0 \mathrm{mmol}$ ) in anhydrous $\mathrm{CH}_{3} \mathrm{CN}(10 \mathrm{~mL})$ was added $\mathrm{K}_{2} \mathrm{CO}_{3}(280 \mathrm{mg}, 2.0 \mathrm{mmol})$ in one portion. Then the reaction mixture was stirred overnight at room temperature under $\mathrm{N}_{2}$ atmosphere. The reaction mixture was concentrated under reduced pressure, and the residue was purified by silica gel column chromatography $(\mathrm{PE} / \mathrm{EtOAc}=5: 1)$ as a yellow solid (315 mg, yield 72\%). Mp: $169.0-169.5{ }^{\circ} \mathrm{C} .{ }^{1} \mathrm{H}$ $\mathrm{NMR}\left(\mathrm{CDCl}_{3}, 400 \mathrm{MHz}\right) \delta=9.26(\mathrm{~d}, J=2.5 \mathrm{~Hz}, 1 \mathrm{H}), 9.10(\mathrm{~d}, J=$ $2.5 \mathrm{~Hz}, 1 \mathrm{H}), 8.69-8.66(\mathrm{~m}, 2 \mathrm{H}), 8.27$ (d, $J=7.7 \mathrm{~Hz}, 1 \mathrm{H}), 7.79$ (dd, $J=7.4 \mathrm{~Hz}, J=7.5 \mathrm{~Hz}, 1 \mathrm{H}), 7.62(\mathrm{~d}, J=8.1 \mathrm{~Hz}, 1 \mathrm{H}), 4.20(\mathrm{t}, J=$ $7.5 \mathrm{~Hz}, 2 \mathrm{H}), 1.76-1.69(\mathrm{~m}, 2 \mathrm{H}), 1.51-1.41(\mathrm{~m}, 2 \mathrm{H}), 0.99(\mathrm{t}, J=$ $7.4 \mathrm{~Hz}, 3 \mathrm{H}) \mathrm{ppm} .{ }^{13} \mathrm{C} \mathrm{NMR}\left(\mathrm{CDCl}_{3}, 100 \mathrm{MHz}\right) \delta=163.8,163.2$, $157.8,152.2$, 147.5, 140.0, 132.1, 131.7, 131.5, 129.6, 128.0, 127.4, 125.1, 123.2, 121.5, 119.4, 40.4, 30.2, 20.4, 13.8 ppm. HRMS (ESI): $m / z\left[\mathrm{M}+\mathrm{H}^{+}\right]$calcd for $\mathrm{C}_{21} \mathrm{H}_{17} \mathrm{~N}_{4} \mathrm{O}_{7}^{+}:$437.1092; found: 437.1086 .

\section{Author contributions}

Y. Zhuo and Y. Zhang contributed equally to this work.

\section{Conflicts of interest}

There are no conflicts to declare.

\section{Acknowledgements}

We gratefully acknowledge financial support from the Scientific Research Foundation of Xiamen Huaxia University (P1001) and Fujian Provincial Colleges and University Engineering Research Center of Biochemical Pharmacy Fund (No. SHZY0001 and No. SHZY201905).

\section{Notes and references}

1 Z. A. Wood, E. Schröder, J. Robin Harris and L. B. Poole, Trends Biochem. Sci., 2003, 28, 32-40.

2 S. Zhang, C.-N. Ong and H.-M. Shen, Cancer Lett., 2004, 208, 143-153.

3 V. I. Abkevich and E. I. Shakhnovich, J. Mol. Biol., 2000, 300, 975-985.

4 H. Refsum, P. M. Ueland, O. Nygård and S. E. Vollset, Annu. Rev. Med., 1998, 49, 31-62.

5 S. Seshadri, A. Beiser, J. Selhub, P. F. Jacques, I. H. Rosenberg, R. B. D'Agostino, P. W. F. Wilson and P. A. Wolf, N. Engl. J. Med., 2002, 346, 476-483.
6 W. Wang, O. Rusin, X. Xu, K. K. Kim, J. O. Escobedo, S. O. Fakayode, K. A. Fletcher, M. Lowry, C. M. Schowalter, C. M. Lawrence, F. R. Fronczek, I. M. Warner and R. M. Strongin, J. Am. Chem. Soc., 2005, 127, 15949-15958.

7 D. M. Townsend, K. D. Tew and H. Tapiero, Biomed. Pharmacother., 2003, 57, 145-155.

8 T. P. Dalton, H. G. Shertzer and A. Puga, Annu. Rev. Pharmacol., 1999, 39, 67-101.

9 D. A. Dickinson and H. J. Forman, Biochem. Pharmacol., 2002, 64, 1019-1026.

10 L.-Y. Niu, Y.-Z. Chen, H.-R. Zheng, L.-Z. Wu, C.-H. Tung and Q.-Z. Yang, Chem. Soc. Rev., 2015, 44, 6143-6160.

11 L. Yi and Z. Xi, Org. Biomol. Chem., 2017, 15, 3828-3839.

12 J. Dai, C. Ma, P. Zhang, Y. Fu and B. Shen, Dyes Pigm., 2020, 177, 108321.

13 C. Yin, F. Huo, J. Zhang, R. Martinez-Manez, Y. Yang, H. Lv and S. Li, Chem. Soc. Rev., 2013, 42, 6032-6059.

14 Q.-Q. Wu, Z.-F. Xiao, X.-J. Du and Q.-H. Song, Chem.-Asian J., 2013, 8, 2564-2568.

15 S. Wu, Y. Li, T. Deng, X. Wang, S. Hu, G. Peng, X.-a. Huang, Y. Ling and F. Liu, Org. Biomol. Chem., 2020, 18, 2468-2474.

16 B. Babür, N. Seferoğlu, M. Öcal, G. Sonugur, H. Akbulut and Z. Seferoğlu, Tetrahedron, 2016, 72, 4498-4502.

17 B. Gao, L. Cui, Y. Pan, G. Zhang, Y. Zhou, C. Zhang, S. Shuang and C. Dong, RSC Adv., 2016, 6, 43028-43033.

18 S. K. Mahato, D. Bhattacherjee and K. P. Bhabak, Chem. Commun., 2020, 56, 7769-7772.

19 K.-H. Hong, D. I. Kim, H. Kwon and H.-J. Kim, RSC Adv., 2014, 4, 978-982.

20 Q. Guo, Y. Zhang, Z.-H. Lin, Q.-Y. Cao and Y. Chen, Dyes Pigm., 2020, 172, 107872.

21 Y. Yang, X. Yang, K. Zhou, M. Jin and W. Li, J. Photochem. Photobiol., A, 2019, 383, 111984.

22 W. Zhao, M. Sun, T. Lei, X. Liu, Q. Zhang and C. Zong, Sens. Actuators, B, 2017, 249, 90-95.

23 Q. Sun, R. Ren, P.-P. Wu, L.-S. Zhuo, H. Dong, H.-T. Peng, Y.-F. Cao, X.-G. Luo and N.-F. She, Dyes Pigm., 2020, 182, 108702.

24 J. Zhou, S. Xu, X. Dong, W. Zhao and Q. Zhu, Dyes Pigm., 2019, 167, 157-163.

25 Y. Li, K.-N. Wang, B. Liu, X.-R. Lu, M.-F. Li, L.-N. Ji and Z.-W. Mao, Sens. Actuators, B, 2018, 255, 193-202.

26 X. Xie, M. Li, F. Tang, Y. Li, L. Zhang, X. Jiao, X. Wang and B. Tang, Anal. Chem., 2017, 89, 3015-3020.

27 H. Zhu, H. Zhang, C. Liang, C. Liu, P. Jia, Z. Li, Y. Yu, X. Zhang, B. Zhu and W. Sheng, Analyst, 2019, 144, 70107016.

28 L. Feng, P. Li, J. Hou, Y.-L. Cui, X.-G. Tian, Z.-L. Yu, J.-N. Cui, C. Wang, X.-K. Huo, J. Ning and X.-C. Ma, Anal. Chem., 2018, 90, 13341-13347.

29 M. J. Frisch, G. W. Trucks, H. B. Schlegel, G. E. Scuseria, M. A. Robb, J. R. Cheeseman, G. Scalmani, V. Barone, G. A. Petersson, H. Nakatsuji, X. Li, M. Caricato, A. V. Marenich, J. Bloino, B. G. Janesko, R. Gomperts, B. Mennucci, H. P. Hratchian, J. V. Ortiz, A. F. Izmaylov, J. L. Sonnenberg, D. Williams-Young, F. Ding, F. Lipparini, F. Egidi, J. Goings, B. Peng, A. Petrone, T. Henderson, 
D. Ranasinghe, V. G. Zakrzewski, J. Gao, N. Rega, G. Zheng, W. Liang, M. Hada, M. Ehara, K. Toyota, R. Fukuda, J. Hasegawa, M. Ishida, T. Nakajima, Y. Honda, O. Kitao, H. Nakai, T. Vreven, K. Throssell, J. A. Montgomery Jr, J. E. Peralta, F. Ogliaro, M. J. Bearpark, J. J. Heyd, E. N. Brothers, K. N. Kudin, V. N. Staroverov, T. A. Keith, R. Kobayashi, J. Normand, K. Raghavachari, A. P. Rendell, J. C. Burant, S. S. Iyengar, J. Tomasi, M. Cossi, J. M. Millam, M. Klene, C. Adamo, R. Cammi,
J. W. Ochterski, R. L. Martin, K. Morokuma, O. Farkas, J. B. Foresman and D. J. Fox, Gaussian 16, Revision C.01, Gaussian, Inc., Wallingford, CT, 2016.

30 I. Ismail, D. Wang, Z. Wang, D. Wang, C. Zhang, L. Yi and Z. Xi, Dyes Pigm., 2019, 163, 700-706.

31 Y. Zhang, X. Shao, Y. Wang, F. Pan, R. Kang, F. Peng, Z. Huang, W. Zhang and W. Zhao, Chem. Commun., 2015, 51, 4245-4248. 